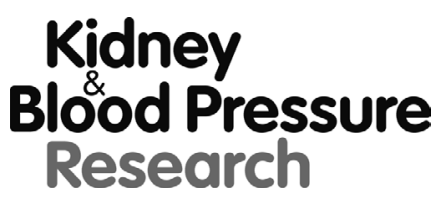

Kidney Blood Press Res 2018;43:793-806

DOI: $10.1159 / 000489915$

Published online: 22 May, 2018

Accepted: 9 May, 2018

This article is licensed under the Creative Commons Attribution-NonCommercial-NoDerivatives 4.0 International License (CC BY-NC-ND) (http//www.kargercom/Services/OpenAccessLicense). Usage and distribution for commercial purposes as well as any distribution of modified material requires written permission.

\title{
Impaired Microcirculation in Children After Kidney Transplantation: Everolimus Versus Mycophenolate Based Immunosuppression Regimen
}

\author{
Stephan Ruben ${ }^{\mathrm{a}} \quad$ Martin Kreuzer $^{\mathrm{a}} \quad$ Anja Büscher ${ }^{\mathrm{b}}$ Rainer Büscher ${ }^{\mathrm{b}}$ \\ Julia Thumfartc Uwe Querfeld ${ }^{c}$ Hagen Staude ${ }^{d}$ Thurid Ahlenstiel-Grunow ${ }^{a}$ \\ Anette Melk ${ }^{a}$ Dagmar-Christiane Fischer ${ }^{d}$ Maren Leifheit-Nestler ${ }^{a} \quad$ Lars Pape $^{a}$ \\ Dieter Haffner ${ }^{a}$ \\ ${ }^{a}$ Dept. of Pediatric Kidney, Liver and Metabolic Diseases, Hannover Medical School, Hannover, ${ }^{b}$ Dept. of \\ Pediatrics II, University Hospital Essen, Essen, 'Dept. of Pediatric Nephrology, Charite Hospital, Berlin, \\ ¿University Children's Hospital Rostock, Rostock, Germany
}

\section{Key Words}

Everolimus • Skin microcirculation • Endothelial dysfunction $\bullet$ Children $•$ Kidney transplantation - Atherosclerosis

\begin{abstract}
Background/Aims: Whether the immunosuppressive regimen is associated with micro- and macro-vascular status in pediatric kidney transplant recipients (KTx) is unknown. Methods: We performed a cross-sectional, case-control study in 44 pediatric KTx patients on either everolimus (EVR) plus calcineurin inhibitor or standard treatment, i.e. mycophenolate mofetil plus calcineurin inhibitor. Measurement of carotid intima-media thickness (CIMT) via ultrasound, central pulse wave velocity (PWV) by a cuff-based oscillometric technique, and skin microvascular blood flow during local heating via laser-Doppler-fluximetry (LDF) served as marker of subclinical vascular disease. Serum concentrations of angiopoietin-1 and -2 , fibroblast-growth factor 23 (FGF23) and soluble klotho were measured. Results: EVR-treated patients exhibited a similar degree of hypertension, increased cIMT, elevated pro-inflammatory angiopoietin-2, and diminished endothelial survival factor angiopoietin-1 compared to healthy children but presented with a twofold more reduced skin micro-vascular function compared to standard treatment (each $\mathrm{p}<0.001$ ). By contrast, PWV and soluble klotho levels were normal in both groups. Conclusion: Endothelial dysfunction seems more frequent in KTx patients on EVR-based immunosuppressive regimen compared to standard immunosuppression.

S. Ruben and M. Kreuzer contributed equally to this work.

\begin{tabular}{ll}
\hline Dieter Haffner, M.D. & Department of Pediatric Kidney, Liver and Metabolic Diseases, Hannover Medical School \\
& Carl-Neuberg-Str. 1, D-30625 Hannover (Germany) \\
& Tel. +49511 5323213 , Fax +49511532 3911, E-Mail Haffner.Dieter@mh-hannover.de
\end{tabular}
\end{abstract}




\section{Kidney Blood Pressure Research}

Kidney Blood Press Res 2018;43:793-806

\begin{tabular}{l|l}
\hline DOI: $10.1159 / 000489915$ & (C) 2018 The Author(s). Published by S. Karger AG, Basel
\end{tabular}

Published online: 22 May, 2018

www.karger.com/kbr

794

\section{Introduction}

Cardiovascular complications are the major cause of the considerably increased mortality in pediatric patients with chronic kidney disease (CKD) [1]. Kidney transplantation (KTx) is the treatment of choice in these patients but mortality rates remain markedly elevated compared to the general population [1]. Impaired microcirculation was noted in pediatric patients with CKD stage 2-3 lacking arterial hypertension and was shown to be associated with mortality rates in adult CKD patients [2-5]. In addition changes in macrocirculation e.g. elevated carotid intima-media thickness (cIMT) and pulse wave velocity (PWV) were found in $40 \%$ and $20 \%$ of children with CKD stage 3, respectively [4]. Although, endothelial function usually improves after KTx, endothelial dysfunction can be detected in up to $72 \%$ of pediatric and adult renal transplant recipients [6-10]. This may be related to pre-transplantation, prevalent, traditional and nontraditional cardiovascular risk factors that can be aggravated by the effects of steroid use after transplantation $[8,11,12]$.

Optical assessment of skin microvascular function has been used for diagnostic purposes in adults for more than 20 years [13-16], and in recent years cutaneous laserDoppler fluximetry (LDF) has become accepted as an easy and noninvasive method to investigate microcirculation and/or the neurogenic vasodilation response secondary to physical or pharmacological stimulation in children [17, 18]. A study of both cross-sectional and longitudinal design in adults with end-stage renal disease revealed that an impaired cutaneous local thermal hyperemic response was associated with increased cardiovascular mortality [5]. An increasing number of studies suggest that cutaneous microcirculation can serve as surrogate parameter for generalized microvascular dysfunction [16, 19-21].

\section{Materials and Methods}

\section{Objective}

Everolimus (EVR) is an inhibitor of mammalian targets of rapamycin (mTOR) and a potent immunosuppressant inhibiting the interleukin-2 stimulated T-cell proliferation pathway [22]. In addition, it has direct inhibitory effects on proliferation of smooth muscle cells, endothelial cells and circulating vascular progenitor cells $[23,24]$. In heart transplant recipients, EVR has been associated with a diminished progression of cardiac allograft vasculopathy [25].

In the absence of studies confirming comparable benefits in kidney transplant recipients we performed a cross-sectional, multicenter, pilot study in stable pediatric kidney transplant recipients comparing patients treated with EVR plus clacineurin inhibitor (CNI) with patients receiving standard treatment, i.e. mycophenolate mofetil (MMF) plus CNI regimen. Clinical evaluation consisted of a comprehensive assessment of the macro- and mirco-vascular system.

\section{Study design}

The local ethics committees approved the study and written informed consent was obtained from patients, healthy controls and/or their guardians. In pediatric kidney transplantation our center at Hannover Medical school has acquired substantial knowledge using mTOR (Everolimus) based immunosuppressive regimen over the past years [26].

Step one inclusion criteria. Patients at Hannover Medical School, aged 6 to 18 years, with a functioning first or second transplant for at least 6 months, on stable Everolimus (EVR) based immunosuppressive regimen for at least 6 months and lack of rejection within this time.

Step two inclusion criteria. Patients at all participating centers with a functioning first or second transplant for at least 6 months, on stable calcineurininhibitor (CNI) based immunosuppressive regimen for at least 6 months and lack of rejection within this time, matched to step one patients by: (i) age, (ii) sex, (iii) first or second transplant, (iv) time since KTx and (v) estimated glomerular filtration rate (eGFR) (Table 1). 


\section{Kidney Blood Pressure Research}

Exclusion criteria. Clinically overt inflammatory disease at the time of investigation or pregnancy.

Patients were identified by via chart review at the centers outpatient transplant clinics.

\section{Participants}

In pre-screening at our center 51 patients with EVRbased immunosuppressive regimen were eligible for this study; 26 patients eventually agreed to take part. Four patients had to be excluded due to technical problems and incomplete data. Twenty-two patients with a full data set were included in final data analysis.

Twenty-two patients with CNI-based (standard) immunosuppressive regimen matched according to criteria mentioned above were recruited at all participating centers: Hannover (EVR n=22; CNI n=8), Essen (CNI $n=7$ ), Berlin (CNI $\mathrm{n}=4$ ), and Rostock (CNI $n=3$ ). All patients were transplanted between 1998 and 2012 .

\section{Setting}

Patients were investigated between 9 am and $12 \mathrm{pm}$ in a period from 2012 to 2015 . This included review of the history, a full physical examination, and collection of blood and urine samples, which were stored at $-80^{\circ} \mathrm{C}$. Thereafter assessment of the vascular status was performed including determination of (i) skin microvascular endothelial function by use of cutaneous LDF (ii) stiffness of the conduit arteries by measurement of pulse wave velocity (PWV), (iii) ultrasound assessment of the carotid intima-media thickness (cIMT), (iv) ambulatory blood pressure monitoring (ABPM) for the following 24 hours. In addition, Data concerning endothelial function (skin microcirculation, serum biomarkers) were compared with a group of healthy children ("healthy controls").

\section{Data sources and measurements}

Immunosupression regimens. All patients received $300 \mathrm{mg}$ prednisolone $/ \mathrm{m}^{2}$ body surface area (BSA) intravenously at the time of engrafting. Prednisolone was discontinued in 19/22 (86.4\%) and 10/22 (45.5 $\%)$ at 1.1 years and 1.8 years after KTx in the EVR and standard group, respectively (each p>0.05). In the EVR group, patients were started on low dose CsA with target trough levels at 50-100 $\mu \mathrm{g} / \mathrm{L}$ in the first 6 months post KTx and 25-75 $\mu \mathrm{g} / \mathrm{L}$ thereafter $[27,28]$. EVR target trough levels were 3-6 $\mathrm{ng} / \mathrm{ml}$ in the first 6 months post KTx and 2-5 $\mu \mathrm{g} / \mathrm{L}$ thereafter [29]. Low dose CsA had been switched to full dose Tacrolimus (TAC) in 5 patients in the EVR group due to biopsy proven rejection. The standard treatment group received

Table 1. Patient characteristics of 44 kidney transplant recipients on everolimus-based immunosuppression and standard
immunosuppression. EVR, everolimus; KTx, kidney transplantation; eGFR, estimated glomerular filtration rate; CAKUT, congenital abnormalities of the kidney and urinary tract; HUS, hemolytic uremic syndrome; SDS, SD score; BMI, body mass index; PD, peritoneal dialysis; HD, hemodialysis; Tac, tacrolimus; CsA, cyclosporine A; * $\mathrm{p}<0.05$ vs. healthy children; n.a., not applicable

\begin{tabular}{|c|c|c|c|}
\hline Parameter & EVR $(\mathrm{n}=22)$ & Standard $(\mathrm{n}=22)$ & $\mathrm{P}$ value \\
\hline Male sex $[\%]$ & 59.1 & 54.6 & 0.9999 \\
\hline Age [years] & $13.47 \pm 0.6$ & $14.92 \pm 0.5$ & 0.0689 \\
\hline Age at KTx [years] & $9.05(1.42-15.08)$ & $10.38(1.42-16.17)$ & 0.7848 \\
\hline Time since KTx [months] & $42(6-168)$ & $66(6-169)$ & 0.3481 \\
\hline eGFR $\left[\mathrm{ml} / \mathrm{min} / 1.73 \mathrm{~m}^{2}\right]$ & $64 \pm 4.00$ & $60.13 \pm 5.91$ & 0.5898 \\
\hline Height [SDS] & $-0.99 \pm 0.22^{*}$ & $-1.38 \pm 0.20^{*}$ & 0.1900 \\
\hline Body weight [SDS] & $-0.40 \pm 0.30$ & $-0.74 \pm 0.31^{*}$ & 0.4338 \\
\hline BMI [SDS] & $0.13 \pm 0.29$ & $-0.06 \pm 0.31$ & 0.6551 \\
\hline Underlying renal diseases & & & 0.9000 \\
\hline CAKUT $[\%]$ & 31.8 & 36.4 & \\
\hline glomerular [\%] & 18.2 & 13.6 & \\
\hline HUS [\%] & 4.6 & 4.6 & \\
\hline hereditary [\%] & 22.7 & 18.2 & \\
\hline others [\%] & 22.7 & 27.3 & \\
\hline \multicolumn{4}{|l|}{ Transplantation modalities } \\
\hline pre-emptive KTx [\%] & 64.3 & 35.7 & 0.3319 \\
\hline living donor transplantation [\%] & 56.6 & 43.8 & 0.7546 \\
\hline previous acute transplant rejection [\%] & 27.3 & 22.7 & 0.9999 \\
\hline \multicolumn{4}{|l|}{ Dialysis modalities } \\
\hline mode of dialysis & & & 0.9999 \\
\hline PD [\%] & 84.6 & 70.6 & \\
\hline $\mathrm{HD}[\%]$ & 15.4 & 29.4 & \\
\hline time on dialysis [days] & $215(0-1205)$ & $188(0-1059)$ & 0.9530 \\
\hline \multicolumn{4}{|l|}{ Immunosupressive therapy } \\
\hline current steroid treatment [\%] & 13.6 & 54.6 & 0.0097 \\
\hline prednisolone dosage $\left[\mathrm{mg} / \mathrm{m}^{2} /\right.$ day $]$ & $0(0-3.4)$ & $1(0-4.6)$ & 0.0091 \\
\hline cumulative prednisolone dosage $[\mathrm{g}]$ & $3.92(1.09-14.88)$ & $6.80(1.27-65.71)$ & 0.0291 \\
\hline Tac treatment $[\%]$ & 22.7 & 68.2 & 0.0058 \\
\hline Tac dosage $\left[\mathrm{mg} / \mathrm{m}^{2} /\right.$ day $]$ & 3.27 (1.31-4.09) & $2.46(0.81-5.44)$ & 0.8660 \\
\hline Tac trough level $[\mathrm{ng} / \mathrm{ml}]$ & $3.9(1.3-6.4)$ & $5.7(4.6-11.2)$ & 0.1181 \\
\hline CsA treatment $[\%]$ & 77.3 & 31.8 & 0.0058 \\
\hline CsA dosage $\left[\mathrm{mg} / \mathrm{m}^{2} /\right.$ day $]$ & $80.4(49.36-128.1)$ & $127.2(67.27-188.9)$ & 0.0085 \\
\hline CsA trough level $[\mu \mathrm{g} / \mathrm{l}]$ & $49(26-87)$ & $80.5(63-129)$ & 0.0094 \\
\hline EVR trough level $[\mu \mathrm{g} / \mathrm{l}]$ & $3.9 \pm 1.26$ & n.a. & \\
\hline
\end{tabular}




\section{Kidney Blood Pressure Research}

an immunosuppressive regimen, which represents the current standard of care for most pediatric KTx patients in Europe, i.e. a CNI-based regimen consisting of CsA or TAC in conjunction with MMF.

Biochemical parameters. In addition to standard hematological and biochemical analyses, ELISA measurements were performed for c-terminal FGF23, sKlotho, angiopoietin-1 and -2 according to the manufactures advice (\#60-6100, \#JP27998: TECO Medical, Neufahrn, Germany; \#DANG10, \#DANG20: R\&D Systems, Minneapolis, USA). Hyperphosphatemia, hypocalcemia, and elevated alkaline phosphatase (ALP) levels were defined according to normal values in the K/DOQI Clinical practice guidelines [30]. The revised Schwartz "bedside formula" was used for assessment of eGFR [31].

Healthy controls. As control group for microvascular function we used data from 82 healthy children, which was obtained previously for another study by our workgroup [18]. Furthermore, normal plasma levels for Ang 1 and Ang 2 were obtained from a group of 38 age-matched healthy children for this study. Age and gender related SD scores (SDS) for sKlotho and FGF23 were calculated by use of published normative values (FGF23) and 80 pediatric in house controls (sKlotho) [32].

Assessment of skin microcirculation and definitions. Skin blood flow was assessed by LDF as previously described [18]. In brief, two laser probes were used with a dual channel laser douplex monitor (VMS-LDF2, Moor Instruments, Axminster, UK) to simultaneously record skin microcirculation at different sites and conditions. A heating device with a central hole for placing the laser probe (SH02 Heater, Moor Instruments, Axminster, UK) to the right volar forearm was used to produce a thermal stimulus at one site, the other probe was used as control. After a rest period of minimum 5 minutes, thermal stimulation started at $31^{\circ} \mathrm{C}$ for 90 seconds. Temperature was gradually increased to $40^{\circ} \mathrm{C}$ and then held for a further 30 minutes. Skin blood flow was recorded, converted and displayed as a graph with 10 points per minute. Mean baseline flow was used to normalize the data of both probes. Response of flow was expressed as $x$-fold of baseline flow. Data from the control probe was subtracted from the data of thermal stimulation to eliminate motion artefacts. Thereafter, the complete area under the curve (AUC), the AUC of axon reflex (AR) (first peak) from start of heating to first nadir of the graph and the peak height of AR were calculated. Total AUC is the best reproducible and least interference-prone parameter $[18,33]$. Therefore, it was chosen as main indicator for endothelial dysfunction, whereas time to AR and AR height were used to assess neurogenic vasodilation response. As in previous studies we defined AUC below $10^{\text {th }}$ percentile as endothelial dysfunction $[18,33]$.

Assessment of arterial stiffness, carotid intima-media thickness, and blood pressure. Carotic-femoral PWV was assessed by use of a portable cardiovascular laboratory "Vicorder" [SMT medical, Würzburg, Germany] as published previously [34]. cIMT was measured by high-resolution B-mode ultrasound using a "Linear TH small parts/musc probe PLT-805AT" (6.2-12 mhz) with a Toshiba Xario XG console (Toshiba Medical Systems GmbH, Neuss, Germany) according to the Mannheim cIMT consensus [35]. Systolic and diastolic office BP (median of three oscillometric measurements) were assessed by using locally available devices. For assessment of ABPM, the same device type (Spacelabs 90207-2Q) was used as previously described [36]. Published normative values in children were used to calculate age- and gender- related SD scores for PWV, cIMT, and office as well as $24 \mathrm{~h}$ BP values [34, 36, 37]. The diagnosis of hypertension was made when office or ABPM BP values exceeded the $95^{\text {th }}$ percentile. Increased PWV or cIMT was defined when the respective values exceeded the $95^{\text {th }}$ percentile.

\section{Bias}

EVR-based regimen was the prevalent used regimen at Hannover Children's Hospital at time of studyimplementation [26]. Unfortunately, only half of potential participants agreed to the time consuming study procedure. So, the number of patients was limited. Given the limited number of pediatric patients on EVR-based immunosuppressive regimen in Germany (one center). Although, we tried to minimize this by carefully matching participants as mentioned above, this could only be a pilot study and may be limited by a potential selection bias. In order to prevent a bias in measurement of skin-microcirculation and assessment of arterial stiffness, carotid intima-media thickness and blood pressure standardized procedures were used, e.g. given daytime of participation in the study, predetermined positions of laser-Doppler probes and 


\section{Kidney Blood Pressure Research}

applied heating-protocols. Due to the overall time consuming protocol (approximately 2 hours), repeated measurements with the same patient were not feasible.

\section{Statistical methods}

Statistical analysis was performed using Prism 7.0 (GraphPad Software, Inc., La Jolla, USA) and IBM SPSS Statistics 24.0 (International Business Machines Corp., Armonk, USA). The level of significance was set at a $p<0.05$. Normal distribution was tested with the Kolmogorov Smirnov Test and normally distributed data are given as mean \pm SD whereas median and range is given for non-normally distributed data. In testing for significant differences, the t-test was used for normally distributed data, otherwise the Mann Whitney U-test was applied. Differences in subgroups were tested using Fisher's exact test. Potential predictors of LDF AUC, endothelial dysfunction (LDF AUC $<10^{\text {th }}$ percentile), PWV, and cIMT were identified by using Spearman's rank correlation. Variables from this single regression analysis with a p-value $<0.1$ were transferred to a multiple linear regression analyses model using a stepwise technique to identify independent predictors of vascular status.

\section{Results}

\section{Patient characteristics}

Patients were investigated after a mean period of 5.2 years post KTx with a mean age of 14.8 years, and a mean eGFR of $62 \mathrm{ml} / \mathrm{min}$ per $1.73 \mathrm{~m}^{2}$ (Table 1). Mean time on dialysis and mode of dialysis treatment prior to KTx, the number of previous transplant rejections, and underlying renal diseases did not differ between groups (each $p>0.05$ ) (Table 1). The proportion of living-related and preemptive KTx was higher in the EVR group compared to the standard treatment group, although this did not reach statistical significance. The percentage of patients on daily glucocorticoid therapy and the cumulative steroid exposure was significantly lower in the EVR group compared to the standard treatment group (each $\mathrm{p}<0.01$ ).

\section{Main results}

Hypertension. The vast majority of patients $(87 \%)$ received antihypertensive drugs. Its prevalence and the use of angiotensin-converting enzyme inhibitors (ACEI) or betablockers were comparable in both groups (Table 2). Mean daytime and nighttime 24-hour MAP values were similarly elevated in both patient groups compared to healthy children (each p $>0.05$ EVR vs. standard) (Table 2). Using the $95^{\text {th }}$ percentile of 24-hour MAP values, 6 patients $(27.3 \%)$ in the EVR group and 3 patients $(14.3 \%)$ in the standard treatment group were hypertensive $(p=0.456)$. Using the $95^{\text {th }}$ percentile of office BP values, 7 patients $(33.3 \%)$ in the EVR group and 6 patients $(35.3 \%)$ in the standard treatment group were hypertensive $(\mathrm{p}=0.993)$.

Endothelial function. All parameters of skin microcirculation were significantly diminished in KTx patients compared to healthy controls. The mean skin blood flow was reduced by approximately $50-60 \%$ compared to healthy children with respect to total AUC (196 (28-583) vs. 489 (165-990) rPU*min), AUC of axon reflex (18 (2.5-81) vs. 49 (10-55) rPU*min), and axon reflex amplitude (6.6 (2-24) vs. 13 (6-30) rPU), respectively (each $\mathrm{p}<0.001$ ). Endothelial dysfunction (LDF AUC $<10^{\text {th }}$ perc.) was seen in $77 \%$ of patients. Moreover, there were significant differences in microcirculation measurements between groups of KTx patients (Table 2). In the EVR group, mean total AUC, AUC axon reflex, and axon reflex amplitude were significantly lower compared to the standard group (each $\mathrm{p}<0.01$; Fig. 1A-1C). All EVR patients showed endothelial dysfunction (LDF AUC $<10^{\text {th }}$ perc.), whereas this was observed in only 12 patients $(55 \%)$ in the standard treatment group $(\mathrm{p}<0.001)$. 


\section{Kidney \\ Blood Pressure Research}

Table 2. Endothelial function and vascular status of 44 kidney transplant recipients on everolimusbased immunosuppression versus standard immunosuppression. LDF, laser-Doppler fluximetry; AUC, area under the curve; AR, axon reflex; cIMT, carotid intima-media thickness; SDS, SD score; MAP, mean arterial pressure; BP, blood preasure; ACE, angiotensin converting enzyme; $\mathrm{ARB}$, angiotensin receptor blocker; ${ }^{*} \mathrm{p}<0.001$ vs. healthy children; ${ }^{*} \mathrm{p}<0.05$ vs. healthy children

\begin{tabular}{|c|c|c|c|}
\hline Parameter & EVR $(n=22)$ & Standard $(\mathrm{n}=22)$ & $\mathrm{P}$ value \\
\hline \multicolumn{4}{|l|}{ LDF } \\
\hline $\mathrm{AUC}\left[\mathrm{rPU}^{*} \mathrm{~min}\right]$ & $118.2 \pm 13.84^{\#}$ & $274.4 \pm 34.45^{\#}$ & 0.0001 \\
\hline AUC AR [rPU * min] & $14.3(3.52-35.1)^{\#}$ & $22.6(2.53-81.0)^{\#}$ & 0.0063 \\
\hline AR Amplitude [rPU] & $5.79 \pm 0.53^{\#}$ & $9.93 \pm 1.22^{\#}$ & 0.0035 \\
\hline \multicolumn{4}{|l|}{ cIMT } \\
\hline$[\mathrm{mm}]$ & $0.48(0.39-0.58)$ & $0.47(0.30-0.65)$ & 0.4715 \\
\hline [SDS] & $1.72(0.38-3.86)^{*}$ & $1.43(-1.4-4.39)^{*}$ & 0.5830 \\
\hline \multicolumn{4}{|l|}{ PWV } \\
\hline$[\mathrm{m} / \mathrm{s}]$ & $4.83 \pm 0.46$ & $5.11 \pm 0.91$ & 0.1076 \\
\hline [SDS] & $-0.01 \pm 0.26$ & $0.61 \pm 0.42$ & 0.2162 \\
\hline \multicolumn{4}{|l|}{$\begin{array}{r}\text { 24h MAP } \\
\text { daytime }\end{array}$} \\
\hline$[\mathrm{mmHg}]$ & $90(81$ - 105) & $88.5(82-108)$ & 0.3594 \\
\hline [SDS] & $0.79(-0.48-2.89)^{*}$ & $0.26(-0.46-4.38)^{*}$ & 0.3076 \\
\hline \multicolumn{4}{|l|}{ nighttime } \\
\hline$[\mathrm{mmHg}]$ & $76(64-88)$ & $77(66-107)$ & 0.8325 \\
\hline$[\mathrm{SDS}]$ & $0.91(-1.46-2.42)^{*}$ & $0.76(-0.96-7.19)^{*}$ & 0.4444 \\
\hline$>95^{\text {th }}$ perc. $[\%]$ & 14.3 & 27.3 & 0.4566 \\
\hline \multicolumn{4}{|l|}{ Office BP } \\
\hline \multicolumn{4}{|l|}{ systolic } \\
\hline$[\mathrm{SDS}]$ & $0.90 \pm 0.23 *$ & $0.60 \pm 0.57^{*}$ & 0.5805 \\
\hline \multicolumn{4}{|l|}{ diastolic } \\
\hline$[\mathrm{mmHg}]$ & $70.1 \pm 1.7$ & $75.2 \pm 3.1$ & 0.1339 \\
\hline [SDS] & $0.57 \pm 0.25^{*}$ & $0.98 \pm 0.54$ & 0.4382 \\
\hline$>95^{\text {th }}$ perc. $[\%]$ & 33.3 & 35.3 & 0.9998 \\
\hline \multicolumn{4}{|l|}{ Antihypertensive therapy } \\
\hline patients treated $[\%]$ & 86.4 & 86.4 & 0.9999 \\
\hline number of drugs & $1.91 \pm 0.28$ & $1.96 \pm 0.28$ & 0.9040 \\
\hline ACE or ARB inhibitors [\%] & 68.2 & 54.6 & 0.5365 \\
\hline betablockers [\%] & 40.9 & 54.6 & 0.5467 \\
\hline
\end{tabular}

Pulse wave velocity and cIMT. Mean PWV SDS of KTx patients did not significantly differ from healthy children irrespective of the immunosuppressive regimen (Fig. 2 and Table 2). Only 1 patient (4.5\%) in the EVR group and 4 patients $(18 \%)$ in the standard group demonstrated elevated PWV $(p=0.175)$. Mean cIMT SDS was comparably elevated in both patient groups compared to controls (each $\mathrm{p}<0.01$ vs. healthy children). Increased cIMT was noted in 7 patients $(36.8 \%)$ and 6 patients (35.3\%) in the EVR group and the standard group, respectively ( $p=0.999$; Fig. 2).

Serum markers of vascular health. Mean serum angiopoetin-1 levels were reduced and angiopoietin-2 levels were elevated in both treatment groups, resulting in a markedly increased angiopoietin-2/angiopoietin-1

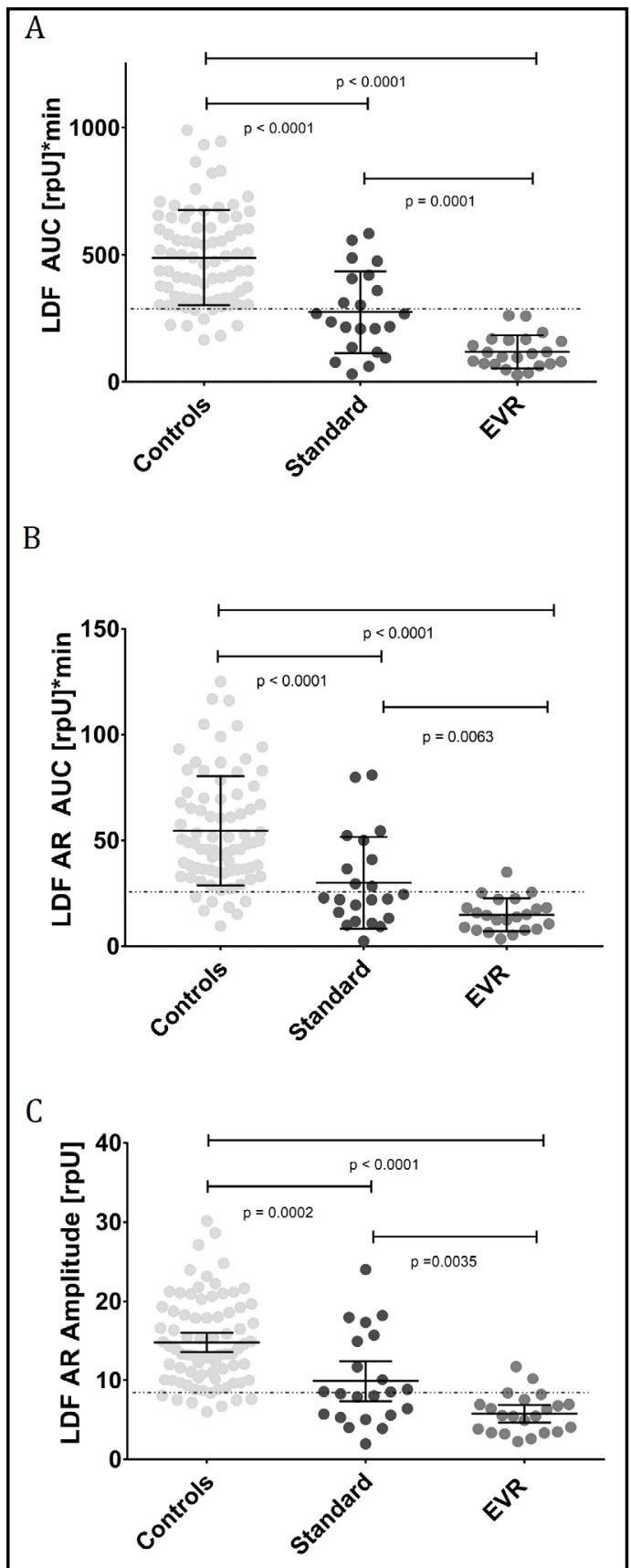

Fig. 1. A-C: Skin microcirculation as assessed by area under the curve (AUC), axon reflex (AR) AUC, and axon reflex amplitude during local heating induced vasodilation in kidney transplant recipients on everolimus-based immunosuppression (EVR, grey circles) versus standard immunosuppression (Standard, dark grey circles), and healthy controls (Controls, light grey circles); rpU, relative perfusion unit; broken horizontal lines indicate the $10^{\text {th }}$ percentile in healthy controls. 


\section{Kidney \\ Blood Pressure Research}

Kidney Blood Press Res 2018;43:793-806

\begin{tabular}{l|l}
\hline DOI: $10.1159 / 000489915$ & (C) 2018 The Author(s). Published by S. Karger AG, Basel
\end{tabular}

Published online: 22 May, 2018 www.karger.com/kbr
Fig. 2. Pulse wave velocity (PWV) and carotid intimamedia thickness (cIMT) in kidney transplant recipients on everolimus-based immunosuppression (EVR, red circles) versus standard immunosuppression (Standard, blue circles). Broken horizontal lines indicate the upper (+2SD) and lower (-2SD) normal range, respectively. ${ }^{*} \mathrm{p}<0.001$ compared to healthy controls. Mean PWV SDS and cIMT SDS did not significantly differ between the EVR and standard treatment group.

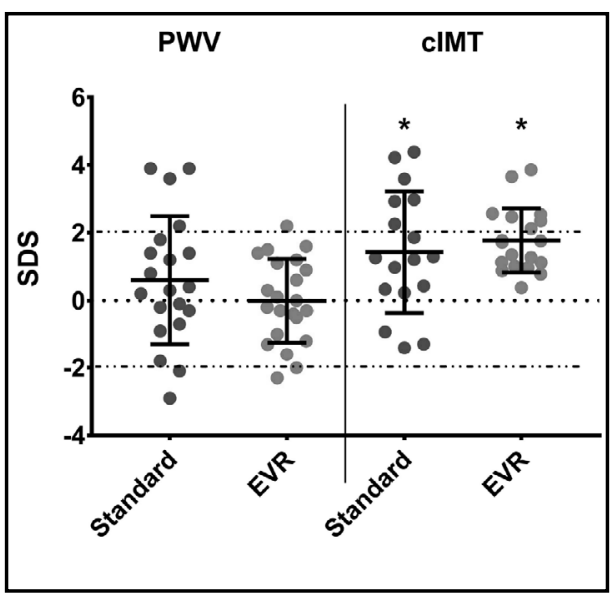

Fig. 3. A-C: Serum angiopoietin 1, angiopoietin 2, and angiopoietin-2/angiopoietin-1 ratio (Ang2-/Ang-1 ratio) in kidney transplant recipients on everolimus basedimmunosuppression (EVR, grey circles) versus standard immunosuppression (Standard, dark grey circles), and healthy controls (Controls, light grey circles).

ratio compared to healthy controls (Fig. 3A3C, Table 3). Angiopoetin-1 levels were lower in EVR than in the standard treatment group, although this did not reach statistical significance $(\mathrm{P}>0.05)$. Compared to healthy children, mean serum FGF23 SDS levels were significantly elevated in the standard treatment group only. Total and albumin-adjusted serum calcium levels were significantly higher in the standard treatment group compared to the EVR group. Likewise, patients in the EVR group were more frequently hypocalcemic $(40.1 \%$ vs. $0 \%, \mathrm{p}<0.01)$, whereas hyperphosphatemia was observed more frequently in the standard treatment group (50.0\% vs. $18.2 \%, \mathrm{p}<0.01)$. Serum ALP levels were increased above the normal range in $50.0 \%$ and $38.1 \%$ in the EVR and standard treatment group, respectively $(p=0.751)$. Mean serum cholesterol levels were significantly higher and hemoglobin levels were lower in EVR compared to the standard treatment group (each $\mathrm{p}<0.05$ ). By contrast, mean serum levels of sKlotho, and 25-hydroxyvitamin D were normal irrespective of treatment. (Table 3).

Predictors of endothelial function, $P W V$, and cIMT

Results of univariate correlation analysis of variables associated with endothelial function, PWV, and cIMT is shown in Table 4. Multiple linear regression analysis revealed EVR

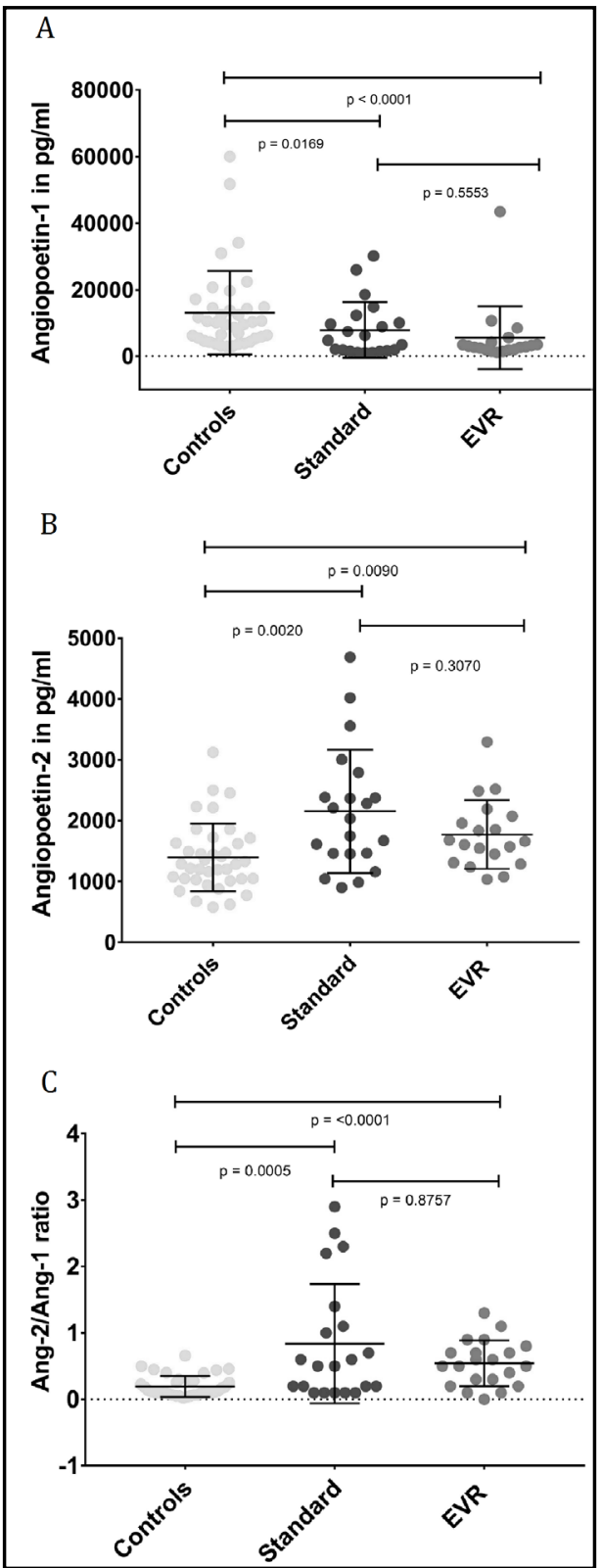




\section{Kidney Blood Pressure Research}

Table 3. Markers of vascular health in kidney transplant recipients on everolimus-based immunosuppression versus standard immunosuppression. Ang, angiopoetin; FGF23, fibroblast growth factor 23; sKlotho, soluble Klotho; SDS, SD score; *p<0.05 vs. healthy controls

\begin{tabular}{|c|c|c|c|}
\hline Parameter & $\operatorname{EVR}(n=22)$ & Standard $(n=22)$ & P value \\
\hline Angiopoetin-1 [pg/ml] & $2838(1159-43485)^{*}$ & 4746 (1027-30212)* & 0.5553 \\
\hline Angiopoetin-2 [pg/ml] & $1658(1036-3294)^{*}$ & 2035 (900-4688)* & 0.3070 \\
\hline Ang-1/Ang-2 ratio & $0.5(0-1.3)^{*}$ & $0.1(0-2.9)^{*}$ & 0.8757 \\
\hline \multicolumn{4}{|l|}{ sKlotho } \\
\hline$[\mathrm{pg} / \mathrm{ml}]$ & $2829(503-8598)$ & 2192 (278-14739) & 0.0653 \\
\hline [SDS] & $0.28(-1.3-2.54)$ & $-0.43(-2.1-3.27)$ & 0.0601 \\
\hline \multicolumn{4}{|l|}{ FGF23 } \\
\hline$[\mathrm{RU} / \mathrm{ml}]$ & $50.45(5.73-476)$ & $117.4(27.67-260)$ & 0.0099 \\
\hline [SDS] & $1.03(-4.1-7.17)$ & $1.33(-2.1-4.32)^{*}$ & 0.0128 \\
\hline \multicolumn{4}{|l|}{ Calcium } \\
\hline$[\mathrm{mmol} / \mathrm{l}]$ & $2.37 \pm 0.02$ & $2.47 \pm 0.02$ & 0.0038 \\
\hline adjusted [mmol/l] & $2.29(2.1-5.44)$ & $2.36(2.21-2.66)$ & 0.0096 \\
\hline Albumin [g/l] & $43.64 \pm 0.53$ & $43.67 \pm 0.53$ & 0.9614 \\
\hline Phosphate [mmol/l] & $1.36 \pm 0.27$ & $1.36 \pm 0.24$ & 0.9763 \\
\hline Alkaline phosphatase [U/l] & $234.3 \pm 25.07$ & $194 \pm 22.71$ & 0.2400 \\
\hline 25-hydroxyvitamin $\mathrm{D}[\mu \mathrm{g} / \mathrm{l}]$ & $25.4(10.51-37.54)$ & $25.36(5.92-43.8)$ & 0.3730 \\
\hline 25-hydroxyvitamin $\mathrm{D}>30 \mu \mathrm{g} / \mathrm{l}$ & $54.6 \%$ & $45.5 \%$ & 0.7195 \\
\hline iPTH $[\mathrm{ng} / \mathrm{l}]$ & $68.35(20.9-215)$ & $58.95(32.9-457)$ & 0.6672 \\
\hline Creatinine $[\mu \mathrm{mol} / \mathrm{l}]$ & $84.15(55.7-293)$ & $103.4(46.9-396)$ & 0.3022 \\
\hline Blood urea $[\mathrm{mmol} / \mathrm{l}]$ & $8.35(4-19.4)$ & $7.6(3.7-25.3)$ & 0.3421 \\
\hline Cholesterol [mg/dl] & $198.7 \pm 9.64$ & $164.2 \pm 10.18$ & 0.0181 \\
\hline Triglycerides [mg/dl] & $151(45-831)$ & $121(48-411)$ & 0.4924 \\
\hline Hemoglobin $[\mathrm{mg} / \mathrm{dl}]$ & $11.63 \pm 0.26$ & $12.55 \pm 0.30$ & 0.0259 \\
\hline Albuminuria $[\mathrm{g} / \mathrm{mmol}]$ & $1.98(0.54-33)$ & $4.41(0.34-347)$ & 0.1969 \\
\hline
\end{tabular}

Table 4. Correlation analysis of variables associated with endothelial function, pulse wave velocity, and carotid intima-media thickness. LDF, laser-Doppler fluximetry; AUC, area under the curve; PWV, pulse wave velocity; cIMT, carotid intima-media thickness; SDS, SD score; BP, blood preasure; EVR, everolimus; KTx, kidney transplantation; Tac, tacrolimus; CsA, cyclosporine A; ALP, alkaline phosphatase; ULN, upper limit of normal level; FGF23, fibroblast growth factor-23

\begin{tabular}{|c|c|c|c|c|}
\hline Parameter & LDF AUC & $\begin{array}{c}\text { LDF AUC } \\
<10^{\text {th }} \text { perc. } \\
\end{array}$ & PWV SDS & cIMT SDS \\
\hline Age [years] & $r=0.378 ; p=0.011$ & $r=-0.339 ; p=0.013$ & & \\
\hline Sex [female] & $r=0.428 ; p=0.004$ & $r=-0.289 ; p=0.030$ & & \\
\hline Age at KTx [years] & $r=0.287 ; p=0.009$ & & & \\
\hline Diastolic office BP [SDS] & & & $r=0.497 ; p=0.020$ & \\
\hline EVR treatment & $r=-0.523 ; p<0.001$ & $r=0.640 ; p<0.001$ & & \\
\hline EVR dosage $\left[\mathrm{mg} / \mathrm{m}^{2} /\right.$ day $]$ & & $\mathrm{r}=0.491 ; \mathrm{p}<0.001$ & & \\
\hline EVR trough level [ $\mu \mathrm{g} / \mathrm{dl}]$ & $r=-0.468 ; p=0.001$ & $r=0.578 ; p<0.001$ & & \\
\hline CsA treatment & $r=-0.334 ; p=0.027$ & $r=0384 ; p=0.005$ & & \\
\hline MMF treatment & $r=0.503 ; p<0.001$ & $\mathrm{r}=-0.586 ; \mathrm{p}<0.001$ & & \\
\hline MMF dosage $\left[\mathrm{mg} / \mathrm{m}^{2} /\right.$ day] & & $r=-0.625 ; p<0.001$ & & \\
\hline TAC treatment & & $r=-0.384 ; p=0.005$ & & \\
\hline TAC dosage $\left[\mathrm{mg} / \mathrm{m}^{2} /\right.$ day $]$ & & $r=-0.303 ; p=0.024$ & & \\
\hline TAC trough level $[\mathrm{ng} / \mathrm{ml}]$ & & & & $r=0.315 ; p=0.061$ \\
\hline Prednisolone treatment & & $r=-0.368 ; p=0.008$ & & \\
\hline Adjusted calcium [mmol/l] & $r=0.319 ; p=0.035$ & $r=-0.325 ; p=0.017$ & & \\
\hline ALP $[\mathrm{U} / \mathrm{l}]$ & $r=-0.436 ; p=0.005$ & & & \\
\hline ALP > ULN & $r=-0.153 ; p=0.174$ & & & \\
\hline iPTH [ng/l] & & & & $r=-0.287 ; p=0.090$ \\
\hline FGF23 [SDS] & & & $r=0.430 ; p=0.002$ & \\
\hline
\end{tabular}




\section{Kidney \\ Blood Pressure Research}

Table 5. Linear regression models of variables associated with endothelial function, pulse wave velocity and carotid intima-media thickness after stepwise variable selection. LDF, laser-Doppler fluximetry; AUC, area under the curve; EVR, everolimus; TAC, tacrolimus; ALP, alkaline phosphatase; UNL, upper limit of normal level; PWV, puls wave velocity; cIMT, carotid intima-media thickness; SDS, SD score; BP, blood preasure

\begin{tabular}{|c|c|c|c|c|}
\hline Outcome & Predictor & Beta $(95 \% \mathrm{CI})$ & P value & Adjusted $\mathrm{r}^{2}$ \\
\hline \multirow{5}{*}{ LDF AUC } & & & & 0.586 \\
\hline & EVR treatment & $-0.424(-185.9 ;-58.5)$ & $<0.001$ & \\
\hline & Sex [female] & $0.421(61.2 ; 182.7)$ & $<0.001$ & \\
\hline & Age [years] & $0.395(8.7 ; 33.8)$ & 0.001 & \\
\hline & ALP $>$ ULN & $-0.321(-157.2 ;-28.7)$ & 0.006 & \\
\hline \multirow[t]{3}{*}{ LDF AUC < 10. perc. } & & & & 0.459 \\
\hline & EVR treatment & $0.625(0.398 ; 0.852)$ & $<0.001$ & \\
\hline & Sex [female] & $-0.271(-0.499 ;-0.043)$ & 0.021 & \\
\hline \multirow[t]{2}{*}{ PWV SDS } & & & & 0.284 \\
\hline & Diastolic office BP [SDS] & $0.552(0.3 ; 0.8)$ & 0.001 & \\
\hline \multirow[t]{2}{*}{ cIMT SDS } & & & & 0.117 \\
\hline & TAC trough level $[\mathrm{ng} / \mathrm{ml}]$ & $0.341(0.1 ; 0.4)$ & 0.042 & \\
\hline
\end{tabular}

treatment, gender, age, and ALP levels above the upper limit of normal as independent predictors of skin microcirculation as measured by the LDF-AUC (Table 5). Neither TAC nor CsA were significantly associated with LDF-AUC and were therefore omitted from the final regression model. Likewise, EVR treatment and male gender were independent predictors of endothelial dysfunction (AUC $<10^{\text {th }}$ percentile), whereas TAC and CsA were not included in the model. PWV SDS was positively associated with diastolic office BP SDS and FGF23 SDS. The TAC trough serum level was the only independent factor associated with cIMT in the multivariable analysis (Table 5).

\section{Discussion}

This is the first pilot study investigating micro-circulation in pediatric patients after kidney transplant (KTx) and comparing different immunosuppressive regimens. The sample size of this pilot study represents about $10 \%$ of children aged 6-18 with working kidney transplant in Germany [38, 39]. In this matched cross-sectional study we found significant differences in micro-vascular parameters between patients treated with either an EVR-based regime or a standard immunosuppressive treatment. Against our expectation, EVR-treated patients showed a profound decrease of skin microvascular function parameters compared to standard treatment patients. Indeed, all patients on EVR showed decreased thermal hyperemic response, whereas this was observed in only half of patients in the standard treatment group. Of note, both groups of KTx patients exhibited a comparable degree of hypertension, increased cIMT, as well as elevated proinflammatory angiopoietin-2 and diminished endothelial survival factor angiopoietin-1 compared to healthy children. Of note EVR treated patients received less CNI and glucocorticoid medication compared to those on standard treatment. Neither TAC nor CsA was associated with skin micro-circulation and endothelial function. Since both, CNI and glucocorticoid medication, are known to impair endothelial function [40] it is unlikely that these discrepancies contributed to the observed higher frequency of endothelial dysfunction in the EVR group.

With Laser-Doppler fluximetry relative changes in skin microcirculation occurring in a small volume (approx. $1 \mathrm{~mm}^{3}$ ) of tissue in response to an exogenous stimulus, i.e. heat, are accurately detected and quantified $[15,17,41]$. Thermal hyperemia response is mediated by two independent phases: The initial rapid phase is predominantly mediated by local sensory nerves and can be significantly attenuated in the presence of local anesthesia [16]. In contrast, the following plateau is mediated by NO, but also by sympathetic neurotransmitters i.e. norepinephrine and neuropeptide Y [42]. Since the development of this method, microvascular dysfunction has been constantly associated with several 


\section{Kidney Blood Pressure Research}

Kidney Blood Press Res 2018;43:793-806

\begin{tabular}{l|l}
\hline DOI: $10.1159 / 000489915$ & (C) 2018 The Author(s). Published by S. Karger AG, Basel
\end{tabular}

Published online: 22 May, 2018

www.karger.com/kb

802

vascular diseases as well as with aging $[16,17,41]$. A correlation between abnormalities in cutaneous microcirculation and microvascular alterations in other organs has been reported for coronary heart disease, retinal vascular damage in diabetes and CKD, among others, suggesting that human cutaneous circulation may be a surrogate marker of systemic microvascular dysfunction in various diseases [17]. One of the most remarkable studies on LDF evaluated thermal hyperemic response using LDF in end-stage renal adults in both crosssectional and longitudinal design [5]. Patients with abnormal cutaneous thermal responses showed significantly increased cardiovascular mortality. This high-risk population was characterized by a markedly diminished local thermal hyperemic response at initial heat peak, nadir and plateau. The most robust parameter in this study was the total area under the curve.

Endothelial dysfunction is characterized by an imbalance between nitric oxide (NO) bioavailability and oxidative stress [43]. Overall, $77 \%$ of patients showed endothelial dysfunction, which is well in line with previous studies in children and adult KTx patients [811]. Several in vitro studies suggest that mTOR inhibitors may impair endothelial cell function by inhibition of endothelial NO synthase (eNOS) activity [44-46]. Moreover, a negative effect of mTOR inhibitors on endothelial-dependent vasodilation was previously described in humans undergoing coronary mTOR-inhibitor-eluting-stent implantation. While use of this type of drug-eluting stents is intended to prevent neo-intimal proliferation [47] a paradoxical, vasoconstrictive response to acetylcholine in the vascular area next to the stent was observed 6 months after implantation [47]. Endothelial senescence has been proposed to be involved in endothelial dysfunction, atherogenesis, and thrombosis. Treatment of human umbilical vein endothelial cells (HUVEC) with sirolimus and everolimus significantly caused a senescent phenotype and plasminogen activator inhibitor 1 up-regulation, associated with a decrease in endothelial eNOS and sirtuin 1 (Sirt1) expression [48]. Sirt1 has been recognized as a key regulator of vascular endothelial homeostasis controlling angiogenesis, endothelial senescence, and dysfunction $[49,50]$. Though, it remains unclear, if the effects of mTOR inhibitors on endothelial cells in-vitro are easily transferable to the complex situation of the whole living body.

The cIMT exceeded the $95^{\text {th }}$ percentile in approximately one third of patients, which is well in line with previous reports in pediatric CKD patients prior to and after KTx [4, 37, 51]. Interestingly, TAC trough levels appeared as the only independent factor associated with cIMT in the present study. However, one has to bear in mind that several other factors were independently associated with cIMT in pediatric CKD patients in larger studies, i.e. physical activity, obesity, and serum phosphorus, which were not fully controlled for in the present study [4]. Aortic stiffness was shown to be an independent predictor of cardiovascular mortality in adult CKD patients [52]. In line with a recent study in a large cohort of predialysis pediatric CKD patients, PWV was independently associated with diastolic BP SDS [4].

Angiopoietin-1 (Ang1) is an endothelial survival factor, whereas angiopoietin-2 (Ang2) shows proinflammatory and anti-angiogenic actions [53, 54]. An Ang1/Ang2 imbalance is thought to be a serum marker for endothelial dysfunction $[33,55,56]$. Reduced serum levels of Ang1 and/or increased Ang2/Ang1 ratios have been reported in pediatric patients with pre-dialysis CKD and hemolytic uremic syndrome and were shown to be significantly associated with cardiovascular measures, e.g. BP and cIMT $[33,56]$. In the present study Ang1/ Ang2 imbalance was frequently present in KTx patients irrespective of immunosuppressive regimen. Comparable studies are missing, but our data suggest, that some serum markers for generalized endothelial dysfunction are still present after kidney transplantation. Further studies are necessary to elucidate this finding.

A recent in vitro study using cultured human coronary artery endothelial cells demonstrated that, in the presence of klotho, FGF23 induces NO release and its stimulating effects on oxidative stress are counterbalanced by increased reactive oxygen degradation [57]. This may at least partly explain the lack of association between endothelial function 


\section{Kidney Blood Pressure Research}

and FGF23 levels in the present study, as sklotho levels were normal in the majority of our patients.

Several limitations of this pilot study must be noted. Patient numbers were low and the follow-up time after KTx was comparatively short (5.2 years) short and thus, within the pediatric age span. Admittedly, even matched carefully, both groups remain heterogenous in many regards and the cross-sectional study design does not allow for drawing conclusions on the progression of vascular damage. Therefore, our findings need further confirmation by longitudinal follow-up in larger patient cohorts to further assess the predictive value of a diminished endothelial function in KTx patients.

\section{Conclusion}

Contrary to our expectations, the patient group treated with EVR showed more hints of endothelial dysfunction in this study of pediatric KTx recipients compared to children with standard immunosuppression regimen. By contrast, the prevalence of increased cIMT and PWV as a measure of premature atherosclerosis and arterial stiffness, respectively, were similar in both groups. Also, there was no significant difference in serum markers for endothelial dysfunction (Ang1/Ang2 ration) between groups. This pilot study highlights the need for subsequent longitudinal studies with larger sample size investigating endothelial (dys-)function and influencing factors in pediatric kidney transplant recipients.

\section{Abbreviations}

EVR (everolimus); KTx (kidney transplantation); eGFR (estimated glomerular filtration rate); CAKUT (congenital abnormalities of the kidney and urinary tract); HUS (hemolytic uremic syndrome); SDS (SD score); BMI (body mass index); PD (peritoneal dialysis); HD (hemodialysis); Tac (tacrolimus); CsA (cyclosporine A); cIMT (carotid intima media thickness); PWV (pulse wave velocity)

\section{Acknowledgements}

This study was supported by the Dr. Robert Pfleger Foundation, Bamberg, Germany.

D.H. and M.K. designed the study. D.H. and M.K. drafted the study protocol. S.R. performed the laser Doppler fluximetry measurements in patients. D.C.F. provided data of healthy controls for vascular parameters. M.L.N. performed the biomarker assays and provided data of healthy controls. A.M. performed measurements for cIMT. S.R., M.K., and D.H. evaluated the data and produced the statistics. S.R., M.K., L.P. and D.H. wrote the first draft of the paper. S.R., M.K., A.B, R.B., J.T., U.Q., L.P., T.A. and H.S. recruited patients for this study. All authors read, revised and approved the manuscript.

\section{Disclosure Statement}

D.H. received consultant fees and/or research grants from Amgen, Horizon Pharma, Kyowa Kirin, Pfizer, and Sandoz. L.P. received research grants and speaker bureau compensation by Novartis and travel costs by Astellas. A.B, R.B, T.A., S.R., M.K., D.C.F., J.T., U.Q, A.M., and H.S. declared that they have no conflict of interest. 


\section{Kidney \\ Blood Pressure Research}

\section{References}

1 Mitsnefes MM: Cardiovascular disease in children with chronic kidney disease. J Am Soc Nephrol 2012;23:578-585.

- Kari JA, Donald AE, Vallance DT, Bruckdorfer KR, Leone A, Mullen MJ, Bunce T, Dorado B, Deanfield JE, Rees L: Physiology and biochemistry of endothelial function in children with chronic renal failure. Kidney Int 1997;52:468-472.

-3 Muscheites J, Meyer AA, Drueckler E, Wigger M, Fischer DC, Kundt G, Kienast W, Haffner D: Assessment of the cardiovascular system in pediatric chronic kidney disease: a pilot study. Pediatr Nephrol 2008;23:22332239.

4 Schaefer F, Doyon A, Azukaitis K, Bayazit A, Canpolat N, Duzova A, Niemirska A, Sözeri B, Thurn D, Anarat A, Ranchin B, Litwin M, Caliskan S, Candan C, Baskin E, Yilmaz E, Mir S, Kirchner M, Sander A, Haffner D, et al.: Cardiovascular Phenotypes in Children with CKD: The 4C Study. Clin J Am Soc Nephrol 2017;12:19-28.

-5 Kruger A, Stewart J, Sahityani R, O’Riordan E, Thompson C, Adler S, Garrick R, Vallance P, Goligorsky MS: Laser Doppler flowmetry detection of endothelial dysfunction in end-stage renal disease patients: correlation with cardiovascular risk. Kidney Int 2006;70:157-164.

-6 Passauer J, Bussemaker E, Lassig G, Gross P: Kidney transplantation improves endothelium-dependent vasodilation in patients with endstage renal disease. Transplantation 2003;75:1907-1910.

7 Kocak H, Ceken K, Yavuz A, Yucel S, Gurkan A, Erdogan O, Ersoy F, Yakupoglu G, Demirbas A, Tuncer M: Effect of renal transplantation on endothelial function in haemodialysis patients. Nephrol Dial Transplant 2006;21:203-207.

8 Morris ST, McMurray JJ, Rodger RS, Farmer R, Jardine AG: Endothelial dysfunction in renal transplant recipients maintained on cyclosporine. Kidney Int 2000;57:1100-1106.

-9 Lilien MR, Stroes ES, Op't Roodt J, de Jongh S, Schroder CH, Koomans HA: Vascular function in children after renal transplantation. Am J Kidney Dis 2003;41:684-691.

-10 Yildirim T, Yilmaz R, Altindal M, Turkmen E, Arici M, Altun B, Erdem Y.: Endothelial dysfunction in renal transplant recipients: role of vitamin D and fibroblast growth factor-23. Transplant Proc 2015;47:343-347.

11 Hausberg M, Kisters K, Kosch M, Rahn KH, Barenbrock M: Flow-mediated vasodilation and distensibility of the brachial artery in renal allograft recipients. Kidney Int 1999;55:1104-1110.

12 Asberg A, Midtvedt K, Vassbotn T, Hartmann A: Better microvascular function on long-term treatment with lisinopril than with nifedipine in renal transplant recipients. Nephrol Dial Transplant 2001;16:1465-1470.

13 Cracowski JL, Minson CT, Salvat-Melis M, Halliwill JR: Methodological issues in the assessment of skin microvascular endothelial function in humans. Trends Pharmacol Sci 2006;27:503-508.

14 Roustit M, Cracowski JL: Non-invasive assessment of skin microvascular function in humans: an insight into methods. Microcirculation 2012;19:47-64.

15 Hellmann M, Roustit M, Cracowski JL: Skin microvascular endothelial function as a biomarker in cardiovascular diseases? Pharmacol Rep 2015;67:803-810.

-16 Minson CT: Thermal provocation to evaluate microvascular reactivity in human skin. J Appl Physiol (1985) 2010;109:1239-1246.

17 Khan F, Elhadd TA, Greene SA, Belch JJ: Impaired skin microvascular function in children, adolescents, and young adults with type 1 diabetes. Diabetes Care 2000;23:215-220.

18 Heimhalt-El Hamriti M, Schreiver C, Noerenberg A, Scheffler J, Jacoby U, Haffner D, Fischer DC: Impaired skin microcirculation in paediatric patients with type 1 diabetes mellitus. Cardiovasc Diabetol 2013;12:115.

19 IJzerman RG, de Jongh RT, Beijk MA, van Weissenbruch MM, Delemarre-van de Waal HA, Serne EH, Stehouwer CD: Individuals at increased coronary heart disease risk are characterized by an impaired microvascular function in skin. Eur J Clin Invest 2003;33:536-542.

20 Khan F, Belch JJ, MacLeod M, Mires G: Changes in endothelial function precede the clinical disease in women in whom preeclampsia develops. Hypertension 2005;46:1123-1128.

21 Khan F, Patterson D, Belch JJ, Hirata K, Lang CC: Relationship between peripheral and coronary function using laser Doppler imaging and transthoracic echocardiography. Clin Sci (Lond) 2008;115:295-300. 


\section{Kidney \\ Blood Pressure Research}

22 Tedesco Silva H Jr, Cibrik D, Johnston T, Lackova E, Mange K, Panis C, Walker R, Wang Z, Zibari G, Kim YS: Everolimus plus reduced-exposure CsA versus mycophenolic acid plus standard-exposure CsA in renaltransplant recipients. Am J Transplant 2010;10:1401-1413.

-23 Marx SO, Jayaraman T, Go LO, Marks AR: Rapamycin-FKBP inhibits cell cycle regulators of proliferation in vascular smooth muscle cells. Circ Res 1995;76:412-417.

24 Fukuda D, Sata M, Tanaka K, Nagai R. Potent inhibitory effect of sirolimus on circulating vascular progenitor cells. Circulation 2005;111:926-931.

25 Hirt SW, Bara C, Barten MJ, Deuse T, Doesch AO, Kaczmarek I, Schulz U, Stypmann J, Haneya A, Lehmkuhl HB: Everolimus in heart transplantation: an update. J Transplant 2013;2013:683964.

26 Pape L, Lehner F, Blume C, Ahlenstiel T: Pediatric kidney transplantation followed by de novo therapy with everolimus, low-dose cyclosporine A, and steroid elimination: 3-year data. Transplantation 2011;92:658662.

27 Brunkhorst LC, Fichtner A, Hocker B, Burmeister G, Ahlenstiel-Grunow T, Krupka K, Bald M, Zapf A, Tonshoff B, Pape L: Efficacy and Safety of an Everolimus- vs. a Mycophenolate Mofetil-Based Regimen in Pediatric Renal Transplant Recipients. PLoS One 2015;10:e0135439.

28 Hocker B, Zencke S, Pape L, Krupka K, Köster L, Fichtner A, Dello Strologo L, Guzzo I, Topaloglu R, Kranz B, König J, Bald M, Webb NJ, Noyal A, Dursun H, Marks S, Ozcakar ZB, Thiel F, Billing H, Pohl M, et al.: Impact of Everolimus and Low-Dose Cyclosporin on Cytomegalovirus Replication and Disease in Pediatric Renal Transplantation. Am J Transplant 2016;16:921-929.

29 Pape L, Ahlenstiel T: mTOR inhibitors in pediatric kidney transplantation. Pediatr Nephrol 2014;29:11191129.

30 K/DOQI Clinical Practice Guidelines for Bone Metabolism and Disease in Children With Chronic Kidney Diseases. American Journal of Kidney Diseases 2005;46:26-28.

-31 Schwartz GJ, Munoz A, Schneider MF, Mak RH, Kaskel F, Warady BA, Furth SL: New equations to estimate GFR in children with CKD. J Am Soc Nephrol 2009;20:629-637.

-32 Fischer DC, Mischek A, Wolf S, Rahn A, Salweski B, Kundt G, Haffner D: Paediatric reference values for the C-terminal fragment of fibroblast-growth factor-23, sclerostin, bone-specific alkaline phosphatase and isoform $5 b$ of tartrate-resistant acid phosphatase. Ann Clin Biochem 2012;49:546-553.

-33 Kreuzer M, Sollmann L, Ruben S, Leifheit-Nestler M, Fischer DC, Pape L, Haffner D: Endothelial dysfunction during long-term follow-up in children with STEC hemolytic-uremic syndrome. Pediatr Nephrol 2017;32:1005-1011.

-34 Fischer DC, Schreiver C, Heimhalt M, Noerenberg A, Haffner D: Pediatric reference values of carotid-femoral pulse wave velocity determined with an oscillometric device. J Hypertens 2012;30:2159-2167.

-35 Touboul P, Hennerici MG, Meairs S, Adams H, Amarenco P, Desvarieux M, Ebrahim S, Fatar M, Hernandez Hernandez R, Kownator S, Prati P, Rundek T, Taylor A, Bornstein N, Csiba L, Vicaut E, Woo KS, Zannad F, Advisory Board of the 3rd Watching the Risk Symposium 2004, 13th European Stroke Conference: Mannheim intima-media thickness consensus. Cerebrovasc Dis 2004;18:346-349.

-36 Wuhl E, Witte K, Soergel M, Mehls O, Schaefer F, German Working Group on Pediatric Hypertension: Distribution of 24-h ambulatory blood pressure in children: normalized reference values and role of body dimensions. J Hypertens 2002;20:1995-2007.

-37 Litwin M, Wühl E, Jourdan C, Trelewicz J, Niemiska A, Fahr K, Jobs K, Grenda R, Wawer ZT, Rajszys P, Tröger J, Mehls O, Schaefer F: Altered morphologic properties of large arteries in children with chronic renal failure and after renal transplantation. J Am Soc Nephrol 2005;16:1494-1500.

38 Frei U, Schober-Halstenberg HJ: QUASINiere Bericht 2006, pp. 25-27. http://www.bundesverband-niere. de/fileadmin/user_upload/QuaSi-Niere-Bericht_2006-2007.pdf.

-39 Kreuzer M, Prüfe J, Oldhafer M, Bethe D, Dierks ML, Müther S, Thumfahrt J, Hoppe B, Büscher A, Rascher W, Hansen M, Pohl M, Kemper MJ, Drube J, Rieger S, John U, Taylan C, Dittrick K, Hollenbach S, Klaus G, et al.: Transitional Care and Adherence of Adolescents and Young Adults After Kidney Transplantation in Germany and Austria: A Binational Observatory Census Within the TRANSNephro Trial. Medicine (Baltimore) 2015;94:e2196.

40 Trapp A, Weis M: The impact of immunosuppression on endothelial function. J Cardiovasc Pharmacol 2005;45:81-87. 


\section{Kidney \\ Blood Pressure Research}

-41 Roustit M, Cracowski JL: Assessment of endothelial and neurovascular function in human skin microcirculation. Trends Pharmacol Sci 2013;34:373-384.

42 Hodges GJ, Kosiba WA, Zhao K, Johnson JM: The involvement of norepinephrine, neuropeptide Y, and nitric oxide in the cutaneous vasodilator response to local heating in humans. J Appl Physiol (1985) 2008;105:233-240.

-43 Li H, Horke S, Forstermann U: Oxidative stress in vascular disease and its pharmacological prevention. Trends Pharmacol Sci 2013;34:313-319.

44 Reineke DC, Muller-Schweinitzer E, Winkler B, Kunz D, Konerding MA, Grussenmeyer T, Carrel TP, Eckstein FS, Grapow MT: Rapamycin impairs endothelial cell function in human internal thoracic arteries. Eur J Med Res 2015;20:59.

-45 Mohacsi PJ, Tuller D, Hulliger B, Wijngaard PL: Different inhibitory effects of immunosuppressive drugs on human and rat aortic smooth muscle and endothelial cell proliferation stimulated by platelet-derived growth factor or endothelial cell growth factor. J Heart Lung Transplant 1997;16:484-492.

-46 Jeanmart H, Malo O, Carrier M, Nickner C, Desjardins N, Perrault LP: Comparative study of cyclosporine and tacrolimus vs newer immunosuppressants mycophenolate mofetil and rapamycin on coronary endothelial function. J Heart Lung Transplant 2002;21:990-998.

47 Fuke S, Maekawa K, Kawamoto K, Saito H, Sato T, Hioka T, Ohe T: Impaired endothelial vasomotor function after sirolimus-eluting stent implantation. Circ J 2007;71:220-225.

48 Ota H, Eto M, Ako J, Ogawa S, Iijima K, Akishita M, Ouchi Y: Sirolimus and everolimus induce endothelial cellular senescence via sirtuin 1 down-regulation: therapeutic implication of cilostazol after drug-eluting stent implantation. J Am Coll Cardiol 2009;53:2298-2305.

49 Potente M, Dimmeler S: Emerging roles of SIRT1 in vascular endothelial homeostasis. Cell Cycle 2008;7:2117-2122.

50 Potente M, Ghaeni L, Baldessari D, Mostoslavsky R, Rossig L, Dequiedt F, Haendeler J, Mione M, Dejana E, Alt FW, Zeiher AM, Dimmeler S: SIRT1 controls endothelial angiogenic functions during vascular growth. Genes Dev 2007;21:2644-2658.

51 Briese S, Wiesner S, Will JC, Lembcke A, Opgen-Rhein B, Nissel R, Wernecke KD, Andreae J, Haffner D, Querfeld U: Arterial and cardiac disease in young adults with childhood-onset end-stage renal diseaseimpact of calcium and vitamin D therapy. Nephrol Dial Transplant 2006;21:1906-1914.

-52 Ben-Shlomo Y, Spears M, Boustred C, May M, Anderson SG, Benjanmin EJ, Boutouyrie P, Cameron J, Chen CH, Cruickshank JK, Hwang SJ, Lakatta EG, Laurent S, Maldonado J, Mitchell GF, Naijar SS, Newman AB, Ohishi M, Pannier B, Pereira T, et al.: Aortic pulse wave velocity improves cardiovascular event prediction: an individual participant meta-analysis of prospective observational data from 17,635 subjects. J Am Coll Cardiol 2014;63:636-646.

53 Maisonpierre PC, Suri C, Jones PF, Bartunkova S, Wiegand SJ, Radziejewski C, Compton D, McClain J, Aldrich TH, Papadopoulos N, Daly TJ, Savis S, Sato TN, Yancopoulos GD: Angiopoietin-2, a natural antagonist for Tie2 that disrupts in vivo angiogenesis. Science 1997;277:55-60.

54 Kim KT, Choi HH, Steinmetz MO, Maco B, Kammerer RA, Ahn SY, Kim HZ, Lee GM, Koh GY: Oligomerization and multimerization are critical for angiopoietin-1 to bind and phosphorylate Tie2. J Biol Chem 2005;280:20126-20131.

55 Page AV, Tarr PI, Watkins SL, Rajwans N, Petruzziello-Pellegrini TN, Marsden PA, Kain KC, Liles WC: Dysregulation of angiopoietin 1 and 2 in Escherichia coli 0157:H7 infection and the hemolytic-uremic syndrome. J Infect Dis 2013;208:929-933.

56 Shroff RC, Price KL, Kolatsi-Joannou M, Todd AF, Wells D, Deanfield J, Johnson RJ, Rees L, Woolf AS, Long D: Circulating angiopoietin-2 is a marker for early cardiovascular disease in children on chronic dialysis. PLoS One 2013;8:e56273.

57 Richter B, Haller J, Haffner D, Leifheit-Nestler M: Klotho modulates FGF23-mediated NO synthesis and oxidative stress in human coronary artery endothelial cells. Pflugers Arch 2016;468:1621-1635. 